\title{
The Relationship between Diabetes and Obesity across Different Ethnicities
}

\author{
Heather JA Foulds ${ }^{1,2,3}$, Shannon SD Bredin ${ }^{3,4}$ and Darren ER Warburton ${ }^{1,2,3 *}$
}

${ }^{1}$ Cardiovascular Physiology and Rehabilitation Laboratory, University of British Columbia, Canada

${ }^{2}$ Experimental Medicine Program, Faculty of Medicine, University of British Columbia, Canada

${ }^{3}$ Physical Activity Promotions and Chronic Disease Prevention Unit, Canada

${ }^{4}$ Cognitive and Functional Learning Laboratories, University of British Columbia, Canada

\begin{abstract}
The relationship between diabetes and obesity, major contributors to cardiovascular disease, varies with ethnicity; however, only limited information is available regarding Aboriginal and South Asian populations.

Objective: This investigation aimed to identify and compare the relationship between diabetes and dysglycemia, and obesity across several ethnicities.

Methods: White $(n=3593)$, Aboriginal $(n=999)$, East Asian $(n=448)$, and South Asian $(n=222)$ adults were measured directly for body mass index (BMI) and waist circumference. Individuals were identified for diabetes and dysglycemia through reported diagnosis, measured random blood glucose and A1C values. The risk ratios of diabetes and dysglycemia were compared across measures of BMI and waist circumference.

Results: Across all ethnic groups, individuals with greater BMI and waist circumference demonstrated greater risk ratios for diabetes and dysglycemia. Aboriginal and South Asian individuals demonstrated greater risks for diabetes relative to White adults regardless of age, gender, physical activity and body composition. Risks for dysglycemia were greater among East and South Asian adults regardless of covariates, while the increased risk among Aboriginal adults appears to be mediated by waist circumference.
\end{abstract}

Conclusions: Overall, increased risks of diabetes and dysglycemia were observed across all ethnic groups with increased body composition measures.

Keywords: Body composition; Dysglycemia; Abdominal obesity; Aboriginal; South Asian; East Asian

\section{Introduction}

The prevalence of diabetes throughout the western world, and the world in general, has drastically increased in recent years $[1,2]$. An estimated $6.2 \%$ of Canadians are currently living with diagnosed diabetes [3]. Diabetes is associated with significant reductions in life expectancy, and mortality rates among adults with diabetes are twice as high as those without diabetes [3]. Obesity is thought to contribute to the insulin resistance syndrome [4] and as such is often linked to the development of diabetes $[2,4,5]$. Within Canada, an estimated $25.4 \%$ of adults are classified as obese, with a further $36.7 \%$ classified as overweight [6]. The prevalence of obesity and related co-morbidities (including diabetes) are increasingly progressively in western society [4].

Ethnicity has been found to play a role in the development of both obesity and diabetes, even among populations exposed to a similar environment $[4,5]$. Aboriginal/Native American populations have been found to have the highest rates of diabetes [4,7]. East Asian populations have also been found to experience greater predisposition to diabetes, compared to White populations [5]. South Asian populations have long been found to experience greater rates of diabetes, compared to White populations $[8,9]$. Additionally, the prevalence of obesity is found to vary among ethnicities, with Native American/Aboriginal populations demonstrating higher rates of obesity compared to White populations [5]. Among Canadian studies, East Asian populations have been identified as having lower rates of obesity compared to White populations, while South Asians obesity measures were similar to that of the White participants $[10,11]$. Odds ratios for diabetes are highest among Aboriginal and South Asian ethnic groups, while East Asian groups demonstrate odds ratios lower than that of White populations [12].

The relationship between diabetes and obesity has been explored, with some evaluations of ethnic differences in this relationship. Differences in the relationship between fasting insulin concentrations and waist circumference have previously been found to vary by ethnicity [13]. While this relationship has been explored between ethnicities, these investigations have primarily compared MexicanAmerican, non-Hispanic white and African-American populations [13-16]. To date, this relationship has not been gender specifically explored in an ethnically diverse population including South Asian, East Asian, and Canadian Aboriginal populations. Accordingly, this investigation sought to compare this relationship among several ethnic groups, including Aboriginal, East Asian and South Asian populations, examining men and women separately. In this paper, it has been hypothesized that there would be distinct ethnicity-related

${ }^{*}$ Corresponding author: Darren Warburton, Cardiovascular Physiology and Rehabilitation Laboratory, University of British Columbia, 6108 Thunderbird Blvd Vancouver V6T 1Z3, Canada, Tel: 1-604-822-1337; Fax: 1-604-822-9222; E-mail: darrenwb@mail.ubc.ca

Received October 12, 2012; Accepted November 24, 2012; Published November 30, 2012

Citation: Foulds HJA, Bredin SSD, Warburton DER (2012) The Relationship between Diabetes and Obesity across Different Ethnicities. J Diabetes Metab 3 228. doi:10.4172/2155-6156.1000228

Copyright: (c) 2012 Foulds HJA, et al. This is an open-access article distributed under the terms of the Creative Commons Attribution License, which permits unrestricted use, distribution, and reproduction in any medium, provided the original author and source are credited. 
differences in the experiences of diabetes and obesity, among both men and women.

\section{Materials and Methods}

From January 2007 to 2011, 5262 individuals from around the province of British Columbia were evaluated directly for various health measures including obesity and diabetes. These participants included 3632 individuals of White decent, 464 East Asian individuals, 228 South Asian individuals, and 951 Aboriginal individuals. Aboriginal participants in this investigation included both First Nations (94\%) and Métis (6\%) individuals. Ethics approval was obtained through the Clinical Research Ethics Board at the University of British Columbia and written informed consent was obtained from each participant prior to data collection. Participants were recruited at local community centres, community events, and health fairs. Aboriginal participants were additionally recruited through and in collaboration with local First Nations band offices and/or Native Friendship Centres.

Individual characteristics collected included age, sex, height, weight, body mass index (BMI), waist circumference, diagnoses of diabetes and a random blood glucose measure. Ethnicity was self-reported by participants through a questionnaire asking each participant to classify them ethnically, including a list of ethnic groups including Aboriginal, Black/African, East Asian, South Asian, South American, White or Other. Only individuals identifying themselves as Aboriginal, East Asian, White or South Asian were included in this analysis due to the small sample size of remaining/other ethnicities sampled. Physical activity was evaluated using the Healthy Physical Activity Participation Questionnaire [17,18]. Active individuals were those reporting at least 3 days per week of vigorous activity or 5 days per week of moderate intensity activity, meeting the Health Canada recommendations $[19,20]$. Moderately active individuals were defined as those reporting 3-4 days per week of moderate intensity activity, while physically inactive individuals were those reporting $<3$ days per week of moderate or vigorous activity.

Obesity measures included determined calculations of BMI from direct measurements of weight and height, and direct measures of waist circumference. Anthropometric measurements were obtained according to standardized protocols from the Canadian Society for
Exercise Physiology [17]. Height was measured to the nearest $0.1 \mathrm{~cm}$ after removal of shoes, hats, and any hair ornaments. Weight was measured to the nearest $0.2 \mathrm{~kg}$ after participants had removed shoes, jackets, and any heavy objects. The BMI was calculated as weight in kilograms divided by height in metres squared. Waist circumference was measured at the end of exhalation at the World Health Organization waist circumference landmark, the midpoint between the twelfth rib and iliac crest on the right side of the body, while participants crossed their arms over their chest [21].

A non-fasting blood glucose measurement was obtained using the point of care Cholestech LDX system (Cholestech, Inverness Medical, Hawyard, CA). This measure was determined from one finger-prick $35 \mu \mathrm{L}$ blood sample. Among individuals sampled from 2009-2011, a measure of glycosylated haemoglobin, A1C, was obtained (A1C Now+, Bayer, Sunnyvale, CA) from a single $5 \mu \mathrm{L}$ finger-prick blood sample. Diagnoses of diabetes were obtained from participant selfreport. Diabetes was defined as reported diagnoses of diabetes or a non-fasting plasma glucose measurement of $>11 . .1 \mathrm{mmol} \cdot \mathrm{L}^{-1}$ [22], or A1C measurement of $\geq 7.0 \%\left(\geq 53 \mathrm{mmol} \cdot \mathrm{mol}^{-1}\right)$ [23]. Dysglycemia was defined as reported diagnosis of diabetes, a non-fasting plasma glucose measurement of $>7.8 \mathrm{mmol} \cdot \mathrm{L}^{-1}[24]$ or A1C measurement of $\geq 6.0 \%(\geq$ $\left.42 \mathrm{mmol} \cdot \mathrm{mol}^{-1}\right)$.

Statistical analyses were performed using Statistica 9.0 (Stats Soft, Tulsa, OK). Mean, standard deviation, and proportion of diabetes and obesity measures and statuses were calculated for each ethnicity. Comparisons of these rates and characteristics between ethnicities, for each gender, were performed using ANCOVA analyses to allow for adjustments for age and gender differences between ethnicities. The risk ratios were calculated from multiple linear regression analysis, in order to adjust for differences in age and gender between ethnicities and to determine correlates of diabetes and dysglycemia [25]. Statistical significance was considered for all statistical analyses where $P$ values $<0.05$.

\section{Results}

Of the 5275 individuals who participated in this health screening $61.4 \%$ were female. Participants represented a range of ages from 18 to 97 years individuals of a range of health statuses. Table 1 describes

\begin{tabular}{|c|c|c|c|c|c|}
\hline Characteristic & $\begin{array}{l}\text { Aboriginal } \\
(n=951)\end{array}$ & $\begin{array}{l}\text { White } \\
(n=3632)\end{array}$ & $\begin{array}{l}\text { East Asian } \\
(n=464)\end{array}$ & $\begin{array}{l}\text { South Asian } \\
(n=228)\end{array}$ & $P$-value \\
\hline Age (years) $\pm S D$ & $41.5 \pm 12.8 \ddagger$ & $50.6 \pm 16.2$ & $45.5 \pm 14.0 \ddagger$ & $44.4 \pm 13.1 \ddagger$ & $<0.001$ \\
\hline Female n (\%) & $716(75.1) \S$ & $2175(59.9)$ & $279(60.1)$ & $112(49.1) \S$ & $<0.001$ \\
\hline Weight $(\mathrm{kg}) \pm \mathrm{SD}$ & $84.2 \pm 19.4 \dagger$ & $78.3 \pm 17.3$ & $65.0 \pm 13.1 \dagger$ & $73.4 \pm 13.6 \dagger$ & $<0.001$ \\
\hline $\mathrm{BMI}\left(\mathrm{kg} \cdot \mathrm{m}^{-2}\right) \pm \mathrm{SD}$ & $30.8 \pm 6.7 \dagger$ & $27.5 \pm 5.3$ & $24.5 \pm 3.7 \dagger$ & $26.7 \pm 4.5$ & $<0.001$ \\
\hline$W C(\mathrm{~cm}) \pm S D$ & $100.9 \pm 16.6 \dagger$ & $89.7 \pm 14.6$ & $80.8 \pm 10.9 \dagger$ & $89.6 \pm 11.7$ & $<0.001$ \\
\hline Random Blood Glucose $\left(\mathrm{mmol} \cdot \mathrm{L}^{-1}\right) \pm \mathrm{SD}$ & $6.24 \pm 2.38 \dagger$ & $6.03 \pm 1.78$ & $6.21 \pm 1.66$ & $6.34 \pm 2.27$ & $<0.001$ \\
\hline $\begin{array}{l}\mathrm{A} 1 \mathrm{C}(\%) \pm \mathrm{SD} \\
\mathrm{A} 1 \mathrm{C}\left(\mathrm{mmol} \cdot \mathrm{mol}^{-1}\right) \pm \mathrm{SD}\end{array}$ & $\begin{array}{l}5.5 \pm 0.7 \\
37 \pm 8\end{array}$ & $\begin{array}{l}5.5 \pm 0.7 \\
37 \pm 8\end{array}$ & $\begin{array}{l}5.6 \pm 0.3 \\
38 \pm 3\end{array}$ & $\begin{array}{l}5.6 \pm 0.7 \\
38 \pm 8\end{array}$ & 0.80 \\
\hline $\mathrm{SBP}(\mathrm{mmHg}) \pm \mathrm{SD}$ & $117.6 \pm 16.2 \dagger$ & $119.7 \pm 17.4$ & $114.4 \pm 17.7 \dagger$ & $116.4 \pm 15.1 \dagger$ & $<0.001$ \\
\hline $\mathrm{DBP}(\mathrm{mmHg}) \pm \mathrm{SD}$ & $74.0 \pm 10.9 \dagger$ & $72.6 \pm 10.4$ & $71.1 \pm 11.1 \dagger$ & $73.7 \pm 9.9$ & $<0.001$ \\
\hline Diabetes $^{\bar{\delta}} \mathrm{n}(\%)$ & $76(8.0) \dagger$ & $169(4.7)$ & $14(3.0)$ & $18(7.9)$ & $<0.001$ \\
\hline Dysglycemia ${ }^{\varepsilon} \mathrm{n}(\%)$ & $132(13.9)$ & $391(10.8)$ & $68(14.7)$ & $35(15.4)$ & $<0.001$ \\
\hline Physically Inactive n (\%) & $454(47.7) \dagger$ & $1163(32.0)$ & $263(56.7) \dagger$ & $115(50.4) \dagger$ & $<0.001$ \\
\hline Moderately Active n (\%) & $180(18.9)$ & $730(20.1)$ & $75(16.2)$ & $35(15.4)$ & 0.02 \\
\hline Physically Active n (\%) & 317 (33.3)† & $1739(47.9)$ & $126(27.2) \dagger$ & $78(34.2) \dagger$ & $<0.001$ \\
\hline
\end{tabular}

BMI: Body Mass Index; DBP: Diastolic Blood Pressure; SBP: Systolic Blood Pressure; SD: Standard Deviation; WC: Waist Circumference; ${ }^{\circ}$ diabetes Diagnosis: Random Blood Glucose $>11.1 \mathrm{mmol} \cdot \mathrm{L}^{-1}$ or A1C $>6.9 \%\left(>52 \mathrm{mmol} \cdot \mathrm{mol}^{-1}\right)$; ${ }^{\varepsilon}$ Diabetes Diagnosis: Random Blood Glucose $>7.8 \mathrm{mmol} \cdot \mathrm{L}^{-1}$ or $\mathrm{A} 1 \mathrm{C}>5.9 \%\left(>41 \mathrm{mmol} \cdot \mathrm{mol}^{-1}\right)$; $\neq$ Significantly different from White after adjusting for gender; §Significantly different from White after adjusting for age; †Significantly different from White after adjusting for age and gender 
the characteristics of participants from each ethnicity. Average BMI, waist circumference, systolic blood pressure, and diastolic blood pressures were significantly different between ethnicities, even after adjusting for age and gender differences. Aboriginal participants generally demonstrated the highest BMI and waist circumference values, with the highest rates of obesity and abdominal obesity. South Asian populations demonstrated the highest levels of non-fasting plasma glucose and $\mathrm{A} 1 \mathrm{C}$ with the highest rate of dysglycemia. East Asian individuals demonstrated the lowest levels of BMI and waist circumference with the lowest levels of diabetes.

Increased body mass index was associated with increases in both diabetes and dysglycemia (Figures 1A and 1B) among all four ethnic groups. Aboriginal participants demonstrated the greatest increase in the risk ratio of both diabetes and dysglycemia at BMI measures of 31.0 $\mathrm{kg} \cdot \mathrm{m}^{-2}$ and greater. However, the risk ratios of diabetes among East Asian and South Asian individuals were more variable, demonstrating the highest increase in risk ratio at BMI measures of $25.0-26.9 \mathrm{~kg} \cdot \mathrm{m}^{-2}$ and 27.0-28.9 $\mathrm{kg} \cdot \mathrm{m}^{-2}$, respectively. South Asian individuals demonstrated significantly greater risk ratios of dysglycemia at BMI measures 29.0-30.9 $\mathrm{kg} \cdot \mathrm{m}^{-2}$, while East Asian and White adults demonstrated significantly greater risk ratios at BMI measures $>31.0 \mathrm{~kg} \cdot \mathrm{m}^{-2}$. Overall, all four ethnic groups demonstrated significantly greater risk ratios of diabetes among greater BMI measures relative to those with BMI measures of less than $25.0 \mathrm{~kg} \cdot \mathrm{m}^{-2}$.

On comparing risk ratios of diabetes and dysglycemia across increasing waist circumference measures, ethnic variations were observed (Figure 2A). East Asian adults were observed to demonstrate significantly greater risks of diabetes with waist circumference measures above $88.0 \mathrm{~cm}$ (female) or $102.0 \mathrm{~cm}$ (male), with risks more than 12 times greater. The other three ethnic groups demonstrated similar trends with diabetes risks 3-5 times greater than the lowest waist circumference individuals of their respective ethnic groups. All four ethnic groups demonstrated significantly greater risks of dysglycemia among individuals with greater waist circumference measures relative to individuals with the lowest waist circumference measures. The greatest increase in risk was observed among South Asian adults. Significant increases in risk ratios were observed among White, East Asian and South Asian individuals with waist circumference measures in the $84.0-87.9 \mathrm{~cm}$ (female) or $94.0-101.9 \mathrm{~cm}$ (male) ranges. However, Aboriginal individuals were not observed to have increased risk ratios of dysglycemia until the highest waist circumference measures.

In comparing the risk ratios of diabetes and dysglycemia directly between ethnicities, differences were identified (Table 2). Relative to White individuals, Aboriginal and South Asian individuals were found to have significantly higher risks for diabetes, even after adjusting for age, gender, physical activity and body composition. By contrast, no difference was identified between East Asian and White individuals in the risk for diabetes. When comparing the risks of dysglycemia between ethnic groups, different trends occurred. Both East and South Asian populations demonstrated significantly greater risks of dysglycemia relative to White adults, even after adjusting for age, gender, physical activity and body composition. Aboriginal individuals were found to have significantly greater risks for dysglycemia than White individuals when adjusting for age, gender, physical activity and BMI. However, when adjusting for differences in waist circumference between Aboriginal and White individuals, differences in the risk ratios of dysglycemia are not identified.

\section{Discussion}

This investigation was unique in identifying differential relationships of obesity and diabetes between ethnicities, including Aboriginal and South Asian populations. Understanding ethnic differences in the risks and development of diabetes and dysglycemia are important for optimal treatment strategies, as ethnic specific treatment and prevention strategies have recently been endorsed for the treatment of diabetes and cardiovascular disease [26,27]. All four ethnic groups in this investigation were recruited at the same community events, resulting in samples of all four ethnic groups from the same communities. The centralized recruitment of all ethnicities at community events, fairs and community centres likely reduces the selection bias and any regional
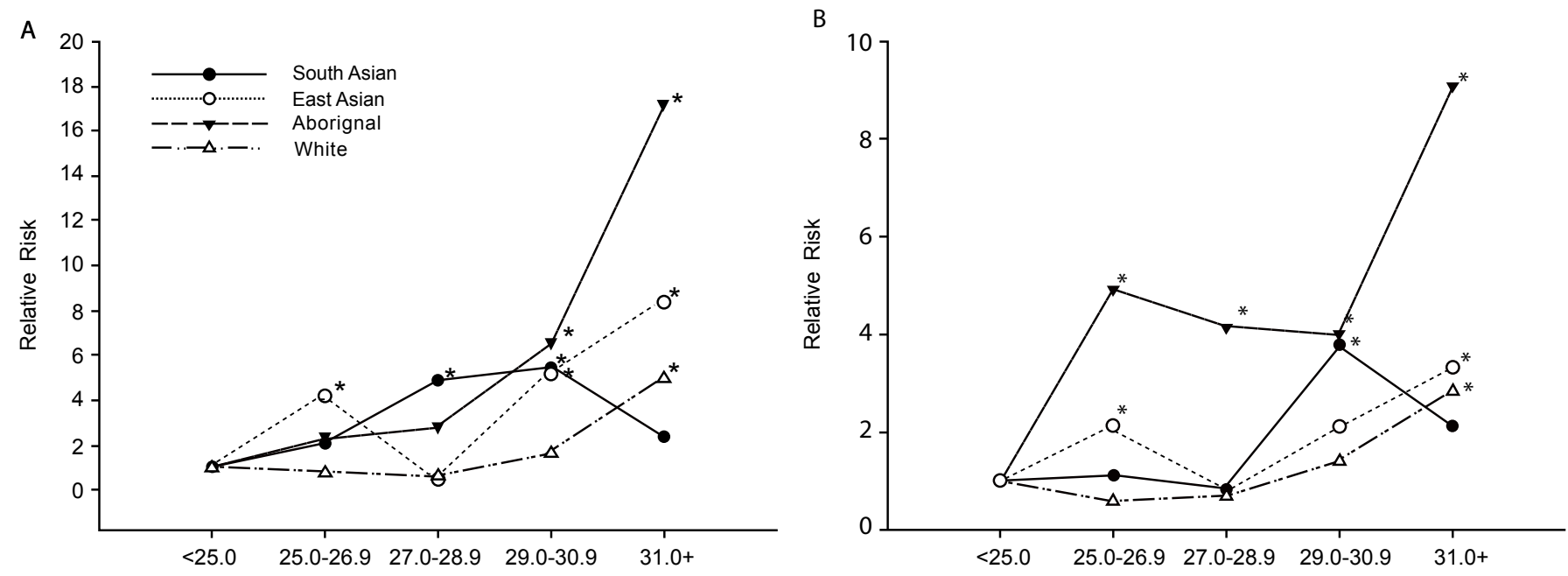

Asterisk $\left({ }^{*}\right)$ indicates significant difference in the risk ratio for diabetes from individuals $<25.0 \mathrm{~kg} \cdot \mathrm{m}^{-2}$, at $p<0.05$

Black circles=South Asian individuals; White circles=East Asian individuals; Black triangles=Aboriginal individuals; White triangles=White individuals

Figure 1: The multiple linear regression risk ratio for diabetes $(A)$ and dysglycemia (B), adjusted for age and gender, across body mass index measures, by ethnic group among participants evaluated from 2007-2011 in British Columbia. 
A

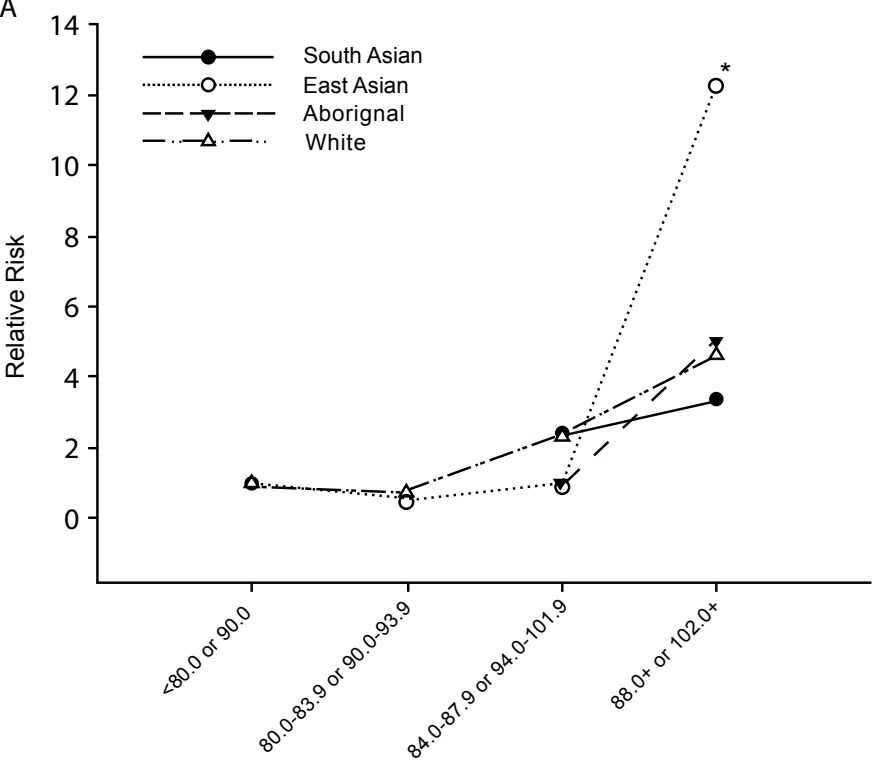

B

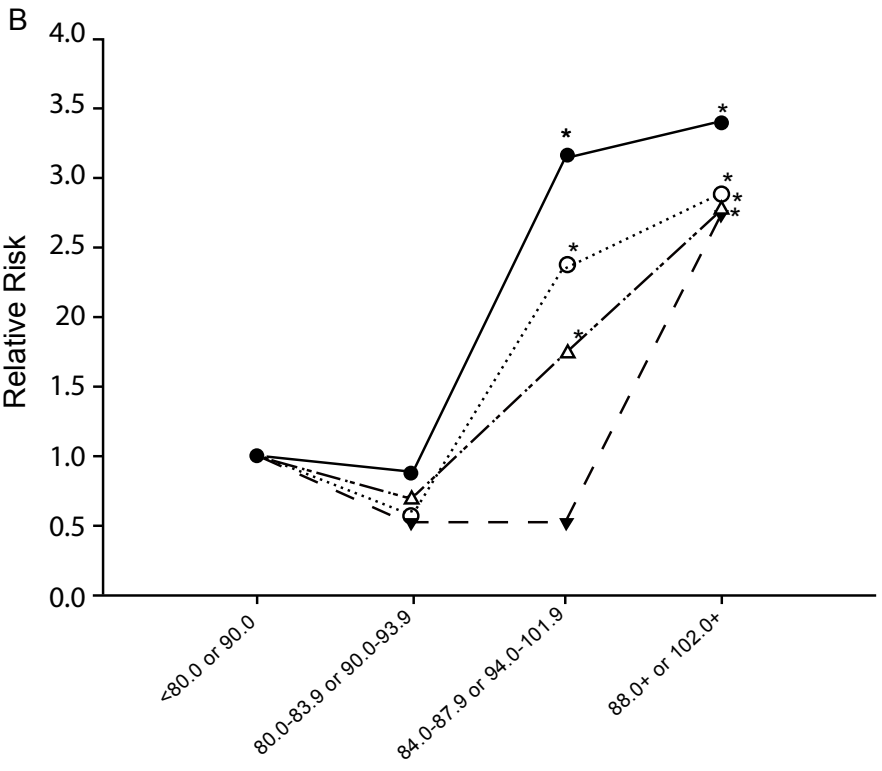

Asterisk $\left({ }^{*}\right)$ indicates significant difference in the risk ratio for diabetes from individuals $<80.0 \mathrm{~cm}$ (female) or $90.0 \mathrm{~cm}$ (male), at $p<0.05$ Black circles=South Asian individuals; White circles=East Asian individuals; Black triangles=Aboriginal individuals; White triangles=White individuals

Figure 2: The multiple linear regression risk ratio for diabetes $(A)$ and dysglycemia (B), adjusted for age and gender, across waist circumference measures, by ethnic group among participants evaluated from 2007-2011 in British Columbia.

\begin{tabular}{|c|c|c|c|c|c|c|c|c|c|c|}
\hline Ethnicity & $\begin{array}{l}\text { Model } 1 \text { RR } \\
(95 \% \mathrm{Cl})\end{array}$ & $P$ value & $\begin{array}{l}\text { Model } 2 \text { RR } \\
(95 \% \mathrm{Cl})\end{array}$ & $P$ value & $\begin{array}{l}\text { Model } 2 \text { and BMI } \\
\text { RR }(95 \% \mathrm{Cl})\end{array}$ & $P$ value & $\begin{array}{l}\text { Model } 2 \text { and WC } \\
\text { RR }(95 \% \mathrm{Cl})\end{array}$ & $P$ value & $\begin{array}{l}\text { Model } 2 \mathrm{BMI} \text { and } \\
\text { WC RR }(95 \% \mathrm{Cl})\end{array}$ & $P$ value \\
\hline \multicolumn{11}{|l|}{ Diabetes } \\
\hline White & 1.00 (referent) & & 1.00 (referent) & & 1.00 (referent) & & 1.00 (referent) & & 1.00 (referent) & \\
\hline Aboriginal & $\begin{array}{l}3.26 \\
(2.47-4.24)\end{array}$ & $<0.001$ & $\begin{array}{l}2.52 \\
(1.55-3.96)\end{array}$ & $<0.001$ & $\begin{array}{l}2.29 \\
(1.69-3.07)\end{array}$ & $<0.001$ & $\begin{array}{l}1.67 \\
(1.20-2.29)\end{array}$ & 0.002 & $\begin{array}{l}1.64 \\
(1.17-2.26)\end{array}$ & 0.004 \\
\hline East Asian & $\begin{array}{l}0.93 \\
(0.54-1.59)\end{array}$ & 0.80 & $\begin{array}{l}0.85 \\
(0.49-1.46)\end{array}$ & 0.56 & $\begin{array}{l}1.24 \\
(0.71-2.12)\end{array}$ & 0.44 & $\begin{array}{l}1.57 \\
(0.90-2.68)\end{array}$ & 0.11 & $\begin{array}{l}1.58 \\
(0.91-2.69)\end{array}$ & 0.10 \\
\hline South Asian & $\begin{array}{l}2.63 \\
(1.63-4.12)\end{array}$ & $<0.001$ & $\begin{array}{l}2.52 \\
(1.55-3.96)\end{array}$ & $<0.001$ & $\begin{array}{l}2.89 \\
(1.79-4.51)\end{array}$ & $<0.001$ & $\begin{array}{l}2.94 \\
(1.82-4.62)\end{array}$ & $<0.001$ & $\begin{array}{l}2.91 \\
(1.79-4.57)\end{array}$ & $<0.001$ \\
\hline \multicolumn{11}{|l|}{ Dysglycemia } \\
\hline White & 1.00 (referent) & & 1.00 (referent) & & 1.00 (referent) & & 1.00 (referent) & & 1.00 (referent) & \\
\hline Aboriginal & $\begin{array}{l}1.84 \\
(1.53-2.20)\end{array}$ & $<0.001$ & $\begin{array}{l}1.78 \\
(1.47-2.14)\end{array}$ & $<0.001$ & $\begin{array}{l}1.87 \\
(1.35-2.53)\end{array}$ & $<0.001$ & $\begin{array}{l}1.18 \\
(0.94-1.46)\end{array}$ & 0.15 & $\begin{array}{l}1.16 \\
(0.92-1.44)\end{array}$ & 0.20 \\
\hline East Asian & $\begin{array}{l}1.67 \\
(1.31-2.10)\end{array}$ & $<0.001$ & $\begin{array}{l}1.56 \\
(1.22-1.98)\end{array}$ & $<0.001$ & $\begin{array}{l}1.95 \\
(1.53-2.46)\end{array}$ & $<0.001$ & $\begin{array}{l}2.16 \\
(1.70-2.70)\end{array}$ & $<0.001$ & $\begin{array}{l}2.17 \\
(1.71-2.72)\end{array}$ & $<0.001$ \\
\hline South Asian & $\begin{array}{l}1.79 \\
(1.30-2.41)\end{array}$ & $<0.001$ & $\begin{array}{l}1.72 \\
(1.24-2.34)\end{array}$ & 0.001 & $\begin{array}{l}1.87 \\
(1.35-2.53)\end{array}$ & $<0.001$ & $\begin{array}{l}1.85 \\
(1.34-2.51)\end{array}$ & $<0.001$ & $\begin{array}{l}1.85 \\
(1.33-2.50)\end{array}$ & $<0.001$ \\
\hline
\end{tabular}

Model 1: Adjusted for age and gender; Model 2: Adjusted for age, gender and physical activity classification (inactive, moderately active or active); BMI: Body Mass Index; WC: Waist Circumference

Table 2: Obesity correlates of diabetes and dysglycemia in Canadians-multiple logistic regression analysis.

or geographic differences. The greater rates of diabetes that was observed among Aboriginal and South Asian populations identified are consistent with that of other published literature $[8,11,28]$. Within the province of British Columbia, the age-adjusted rate of diabetes is 4.8\% [28]. Among Aboriginal populations, we identified a diabetes rate of $8.0 \%$, compared to a national estimate of $6.3 \%$ [12], and greater than the reported provincial rate among First Nations people of 6.7\% [28]. Similarly, among South Asian populations, we identified a rate of $7.9 \%$, compared to $5.6 \%$ in the national survey [12]. Diabetes rates among White and East Asian populations in our investigation were similar to, or slightly higher than rates previously published [12]. While our rates of diabetes are generally found to be higher than that of the national report, it is important to note the difference in data collection between the two investigations. As diabetes rates are known to increase with increasing age [29], the inclusion of 12-16 year old individuals within the national survey may result in under estimations of the true diabetes rates among adult populations. Additionally, the greater rates of diabetes among Aboriginal populations we report may reflect the exclusion of on-reserve individuals among the Canadian Community Health Survey, while our investigation include both on and off reserve Aboriginal populations [12]. We also collected direct assessments of blood glucose and $\mathrm{A} 1 \mathrm{C}$ along with self report, while the national survey reported only self-reports through a telephone survey [12]. A lack of awareness of diabetes may influence the diabetes rates reported. 
Alternatively, the rates of diabetes in our more recent investigation may indicate an increase in diabetes prevalence in recent years.

The connection between obesity and diabetes has long been reported $[2,10,30,31]$. Currently, rates of both obesity and diabetes continue to rise among both developed and developing nations [32]. With these increases in chronic conditions among non-White populations, the relationship between obesity and diabetes is found to differ among ethnicities $[4,33]$. As this relationship may vary between ethnicities, understanding which individuals present the greatest risks for diabetes with increasing body mass provides valuable information for encouraging the most successful treatment and prevention strategies. We identified generally greater rates of diabetes among individuals with greater BMI or waist circumference measures, among all ethnic groups. This finding is expected given outcomes of other investigations $[2,10,30]$. However, the diabetes rates were found to vary between ethnicities. Another Canadian investigation compared the median fasting plasma glucose levels and median A1C levels across quintiles of BMI and waist circumference between the same four ethnic groups [10]. These comparisons found similar trends for increased median fasting plasma glucose or A1C measures among individuals with greater BMI or waist circumference measures [10]. Ethnic differences in the prevalence of diabetes across measures of body composition have similarly been reported previously $[5,8,34]$.

In a previous report, median fasting plasma glucose and $\mathrm{A} 1 \mathrm{C}$ values were generally found to be highest among Aboriginal individuals and lowest among White individuals across all measures of BMI and waist circumference, with similar levels among East Asian and South Asian individuals [10]. This higher level of diabetes and dysglycemia indicators supports our increased risk of diabetes among Aboriginal populations with increasing BMI measures. Similarly, the previously identified elevated levels of fasting plasma glucose, A1C and diabetes prevalence along body composition measures among South Asian populations, relative to White populations support our greater increase in risk of dysglycemia among South Asian populations with increasing waist circumference measurements $[8,10,34]$. We also identified the greatest risk ratio of diabetes among East Asian individuals with the highest BMI measures.

The elevated risk of diabetes and dysglycemia among South Asian populations relative to White, for the same age, gender, physical activity, and body composition suggests the greater development of diabetes among South Asian populations is mediated by factors not investigated in this study. Socio-economic factors [35], genetics [36] and body fat distribution [37] have previously been suggested as causes of this greater risk of diabetes among South Asian populations. Additionally, as South Asian populations demonstrate greater risks of both diabetes and dysglycemia at the same measures of BMI and/or waist circumference, these risk ratios support the use of ethnic-specific body composition guidelines.

Among East Asian populations, the greater risks of dysglycemia at the same levels of BMI and/or waist circumference support the lower obesity definitions among this population. However, the similar risks of diabetes may suggest protective mechanisms reduce the diabetes risk among East Asian populations for the same obesity measure relative to White populations. Diet has been previously implicated as a strong contributor to the development of diabetes, where a diet high in cereal fibre and polyunsaturated fat, and low in Trans fat and glycemic load was associated lower risks of developing diabetes [16]. Further, this reduced risk of developing diabetes with a healthy diet has been found to be stronger among minority populations as compared to the reduction in diabetes risk among white populations maintaining a similar diet [16].

Relative to White populations, Aboriginal populations were identified as having increased risks of diabetes for the same age, gender, physical activity, BMI and/or waist circumference. However, the risks of dysglycemia appear to be mediated by differences in waist circumference as these differences disappear when waist circumference differences are accounted for. Similarly, Aboriginal individuals were found to have the lowest increase in risk ratios of dysglycemia with increases in waist circumference measures (Figure 2B), and the lowest rates of dysglycemia and diabetes among individuals in the lowest waist circumference range (data not shown). These results suggest Aboriginal populations may experience greater rates of dysglycemia due to greater body abdominal obesity. However, the further development of diabetes may be mediated by additional factors beyond body composition. Possible contributing factors include differential experience of gestational diabetes [38], dietary adaptations [39], or development of obesity at a younger age [40], resulting in a greater cumulative effect of obesity at the same age. The mediation of dysglycemia risks among Aboriginal populations through waist circumference supports interventions to reduce waist circumference as a potential means of reducing diabetes and dysglycemia among this population.

Aboriginal individuals demonstrated increased risks for diabetes among the highest BMI range of more than 17 times greater than the lowest BMI range. Similarly, East Asian individuals demonstrated increased risks of diabetes among the highest waist circumference range of more than 12 times that of the lowest waist circumference range. South Asian populations demonstrated the highest rates of dysglycemia and high rates of diabetes and have been found to have greater proportions of visceral abdominal fat for the same waist circumference measures [41]. These results highlight the need for obesity management among all ethnic groups to prevent and manage diabetes and other chronic conditions. While South Asian and Aboriginal populations have previously been highlighted as populations at risk of chronic health conditions, these results identify potential risks among East Asian populations as well $[11,28,42]$.

The cross-sectional design of this investigation limits the ability to determine causality in this relationship. While a relationship between obesity and diabetes is explored, the cause and effect of this relationship cannot be identified. Due to the method of participant recruitment and evaluation of participants at community events, fasting plasma glucose and glucose tolerance measures could not be obtained. A lack of these measures may have resulted in underestimations of the prevalence of diabetes in these populations. Small sample sizes among the South and East Asian populations may also limit the generalizability of these results to a larger population.

\section{Conclusion}

Higher BMI and waist circumference levels are associated with greater prevalence of diabetes among all ethnicities, though increased risks were identified at different BMI and waist circumference ranges among different ethnic groups. Maintenance of weight within health ranges may contribute to prevention and treatment of diabetes among all ethnic groups.

\section{Acknowledgements}

This research was supported by SportMed BC, the Healthy Heart Society of BC the Canadian Society for Exercise Physiology Health and Fitness Program of BC, the Physical Activity Support Line, and ActNow BC. Dr. DER Warburton is the guarantor of this research. This study was supported by funding from the Canada 
Foundation for Innovation, the BC Knowledge Development Fund, the Canadian Institutes of Health Research (CIHR), the Michael Smith Foundation for Health Research (MSFHR), and the Natural Sciences and Engineering Research Council of Canada (NSERC). Dr. Warburton was supported by a CIHR New Investigator Award, and a MSFHR Clinical Scholar Award. Heather Foulds was supported by grants from the National Aboriginal Achievement Foundation, Indspire, and the Foundation for the Advancement of Aboriginal Youth, the University of British Columbia, and an NSERC Postgraduate Scholarship.

\section{References}

1. King H, Aubert RE, Herman WH (1998) Global burden of diabetes, 1995-2025 prevalence, numerical estimates, and projections. Diabetes Care 21: 14141431.

2. Anderson JW, Kendall CW, Jenkins DJ (2003) Importance of weigh management in type 2 diabetes: review with meta-analysis of clinical studies. $J$ Am Coll Nutr 22: 331-339.

3. Centre for Chronic Disease Prevention and Control (2009) Report from the National Diabetes Surveillance System: Diabetes in Canada 2009. Public Health Agency of Canada, Ottawa, Ontario.

4. Cossrow N, Falkner B (2004) Race/ethnic issues in obesity and obesity-related comorbidities. J Clin Endocrinol Metab 89: 2590-2594.

5. Abate N, Chandalia M (2003) The impact of ethnicity on type 2 diabetes. J Diabetes Complications 17: 39-58.

6. Agency of Canada (2011) Obesity in Canada: A joint report from the Public Health Agency of Canada and the Canadian Institute for Health Information. Public Health Agency of Canada, Ottawa, Ontario.

7. Anand SS, Yusuf S, Jacobs R, Davis AD, Yi Q, et al. (2001) Risk factors, atherosclerosis, and cardiovascular disease among Aboriginal people in Canada: the Study of Health Assessment and Risk Evaluation in Aboriginal Peoples (SHARE-AP). Lancet 358: 1147-1153.

8. McKeigue PM, Shah B, Marmot MG (1991) Relation of central obesity and insulin resistance with high diabetes prevalence and cardiovascular risk in South Asians. Lancet 337: 382-386.

9. Mather HM, Chaturvedi N, Fuller JH (1998) Mortality and morbidity from diabetes in South Asians and Europeans: 11-year follow-up of the Southall Diabetes Survey, London, UK. Diabet Med 15: 53-59.

10. Razak F, Anand S, Vuksan V, Davis B, Jacobs R, et al. (2005) Ethnic differences in the relationships between obesity and glucose-metabolic abnormalities: a cross-sectional population-based study. Int J Obes (Lond) 29: 656-667.

11. Anand SS, Yusuf S, Vuksan V, Devanesen S, Teo KK, et al. (2000) Differences in risk factors, atherosclerosis, and cardiovascular disease between ethnic groups in Canada: the Study of Health Assessment and Risk in Ethnic groups (SHARE). Lancet 356: 279-284.

12. Liu R, So L, Mohan S, Khan N, King K, et al. (2010) Cardiovascular risk factors in ethnic populations within Canada: results from national cross-sectional surveys. Open Med 4: e143-153.

13. Karter AJ, Mayer-Davis EJ, Selby JV, D'Agostino RB Jr, Haffner SM, et al. (1996) Insulin sensitivity and abdominal obesity in African-American, Hispanic, and non-Hispanic white men and women. The Insulin Resistance and Atherosclerosis Study. Diabetes 45: 1547-1555.

14. Haffner SM, Stern MP, Hazuda HP, Rosenthal M, Knapp JA, et al. (1986) Role of obesity and fat distribution in non-insulin-dependent diabetes mellitus in Mexican Americans and non-Hispanic whites. Diabetes Care 9: 153-161.

15. Stern MP, Gaskill SP, Hazuda HP, Gardner LI, Haffner SM (1983) Does obesity explain excess prevalence of diabetes among Mexican Americans? Results of the San Antonio Heart Study. Diabetologia 24: 272-277.

16. Shai I, Jiang R, Manson JE, Stampfer MJ, Willett WC, et al. (2006) Ethnicity, obesity, and risk of type 2 diabetes in women: a 20 -year follow-up study. Diabetes Care 29: 1585-1590.

17. Gledhill N, Jamnik V (2003) Canadian Physical Activity, Fitness and Lifestyle Approach. (3rdedn), Ottawa, Canada: Canadian Society for Exercise Physiology.

18. Shephard RJ, Bouchard C (1994) Population evaluations of health related fitness from perceptions of physical activity and fitness. Can J Appl Physiol 19: $151-173$

19. Tremblay MS, Leblanc AG, Janssen I, Kho ME, Hicks A, et al. (2011) Canadian sedentary behaviour guidelines for children and youth. Appl Physiol Nutr Metab 36: $59-64$.

20. Haskell WL, Lee IM, Pate RR, Powell KE, Blair SN, et al. (2007) Physical activity and public health: updated recommendation for adults from the American College of Sports Medicine and the American Heart Association. Circulation 116: 1081-1093.

21. (2000) Obesity: preventing and managing the global epidemic. Report of a WHO consultation. World Health Organ Tech Rep Ser 894: i-xii, 1-253.

22. Oei HH, Vliegenthart R, Hofman A, Oudkerk M, Witteman JC (2004) Risk factors for coronary calcification in older subjects. The Rotterdam Coronary Calcification Study. Eur Heart J 25: 48-55.

23. Canadian Diabetes Association Clinical Practice Guidelines Expert Committee (2003) Canadian Diabetes Association 2003 Clinical Practice Guidelines for the Prevention and Management of Diabetes in Canada. Canadian Journal of Diabetes 27: S1-S152.

24. Gerstein HC, Capes SE (2002) Dysglycemia: a key cardiovascular risk factor Semin Vasc Med 2: 165-174.

25. Zhang J, Yu KF (1998) What's the relative risk? A method of correcting the odds ratio in cohort studies of common outcomes. JAMA 280: 1690-1691.

26. Cardiometabolic Risk Working Group: Executive Committee, Leiter LA, Fitchet $\mathrm{DH}$, Gilbert RE, Gupta M, et al. (2011) Identification and management of cardiometabolic risk in Canada: a position paper by the cardiometabolic risk working group (executive summary). Can J Cardiol 27: 124-131.

27. Leiter LA, Fitchett DH, Gilbert RE, Gupta M, Mancini GB, et al. (2011) Cardiometabolic risk in Canada: a detailed analysis and position paper by the cardiometabolic risk working group. Can J Cardiol 27: e1-e33.

28. British Columbia (2009) Pathways to Health and Healing - 2nd Report on the Health and Well-being of Aboriginal People in British Columbia. Provincial Health Officer's Annual Report 2007. British Columbia Ministry of Healthy Living and Sport Victoria, BC

29. British Columbia (2005) The Impact of Diabetes on the Health and Well-being of People in British Columbia. Provincial Health Officer's Annual Report 2004 British Columbia Ministry of Health Victoria, BC.

30. Hartz AJ, Rupley DC Jr, Kalkhoff RD, Rimm AA (1983) Relationship of obesity to diabetes: influence of obesity level and body fat distribution. Prev Med 12 351-357.

31. Must A, Spadano J, Coakley EH, Field AE, Colditz G, et al. (1999) The disease burden associated with overweight and obesity. JAMA 282: 1523-1529.

32. Hossain P, Kawar B, El Nahas M (2007) Obesity and diabetes in the developing world--a growing challenge. N Engl J Med 356: 213-215.

33. Brancati FL, Kao WH, Folsom AR, Watson RL, Szklo M (2000) Incident type 2 diabetes mellitus in African American and white adults: the Atherosclerosis Risk in Communities Study. JAMA 283: 2253-2259.

34. Chandalia M, Abate N, Garg A, Stray-Gundersen J, Grundy SM (1999) Relationship between generalized and upper body obesity to insulin resistance in Asian Indian men. J Clin Endocrinol Metab 84: 2329-2335.

35. Bhopal R, Hayes L, White M, Unwin N, Harland J, et al. (2002) Ethnic and socio-economic inequalities in coronary heart disease, diabetes and risk factors in Europeans and South Asians. J Public Health Med 24: 95-105.

36. Radha V, Vimaleswaran KS, Babu HN, Abate N, Chandalia M, et al. (2006) Role of genetic polymorphism peroxisome proliferator-activated receptor-gamma2 Pro12Ala on ethnic susceptibility to diabetes in South-Asian and Caucasian subjects: Evidence for heterogeneity. Diabetes Care 29: 1046-1051.

37. Chandalia M, Lin P, Seenivasan T, Livingston EH, Snell PG, et al. (2007) Insulin resistance and body fat distribution in South Asian men compared to Caucasian men. PLoS One 2: e812.

38. Dyck R, Klomp H, Tan LK, Turnell RW, Boctor MA (2002) A comparison of rates, risk factors, and outcomes of gestational diabetes between aboriginal and non-aboriginal women in the Saskatoon health district. Diabetes Care 25 487-493.

39. Williams DE, Knowler WC, Smith CJ, Hanson RL, Roumain J, et al. (2001) The effect of Indian or Anglo dietary preference on the incidence of diabetes in Pima Indians. Diabetes Care 24: 811-816.

40. Young TK, Dean HJ, Flett B, Wood-Steiman P (2000) Childhood obesity in a population at high risk for type 2 diabetes. J Pediatr 136: 365-369. 
Citation: Foulds HJA, Bredin SSD, Warburton DER (2012) The Relationship between Diabetes and Obesity across Different Ethnicities. J Diabetes Metab 3: 228. doi:10.4172/2155-6156.1000228

Page 7 of 7

41. Lear SA, Humphries KH, Kohli S, Birmingham CL (2007) The use of BMI and waist circumference as surrogates of body fat differs by ethnicity. Obesity (Silver Spring) 15: 2817-2824
42. Foulds HJA, Bredin SSD, Warburton DER (2012) Greater prevalence of select chronic conditions among Aboriginal and South Asian participants from an ethnically diverse convenience sample of British Columbians. Appl Physio Nutr Metab 37 